
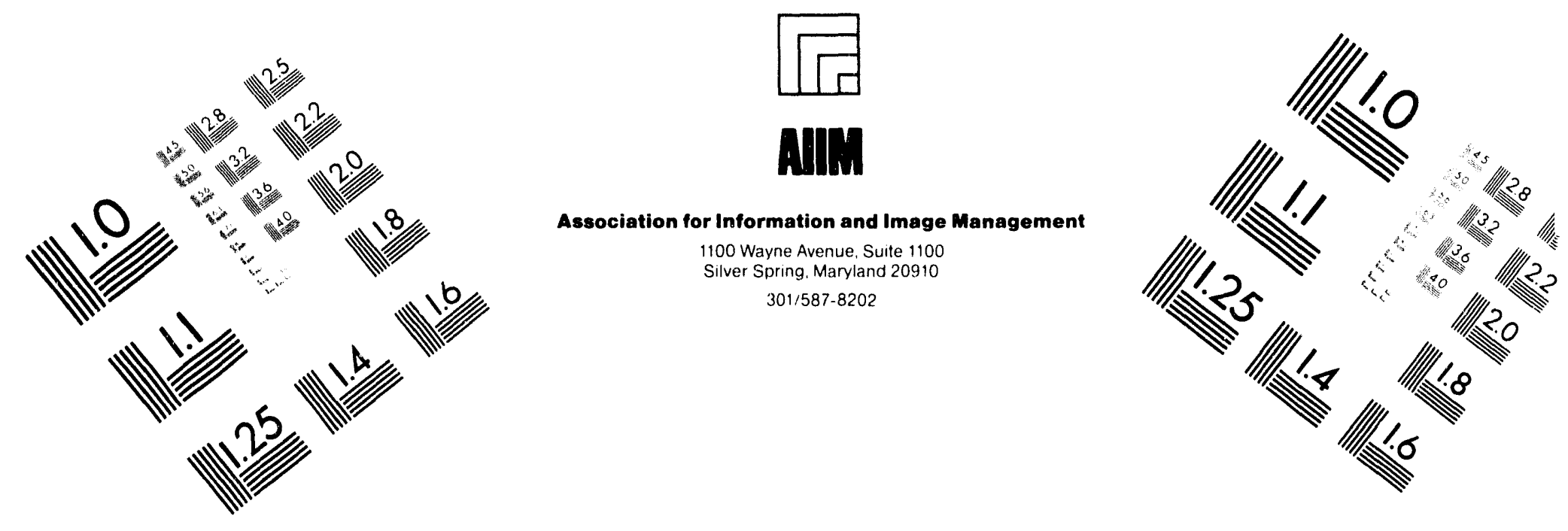

\title{
Centimeter
}

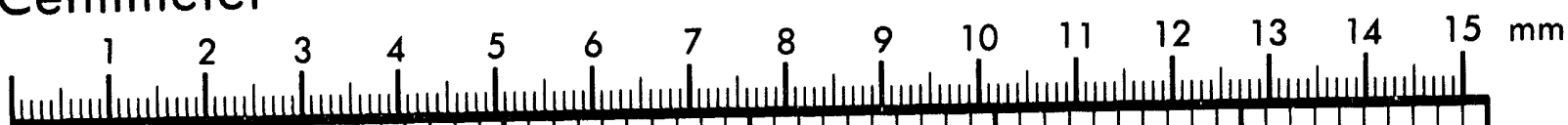

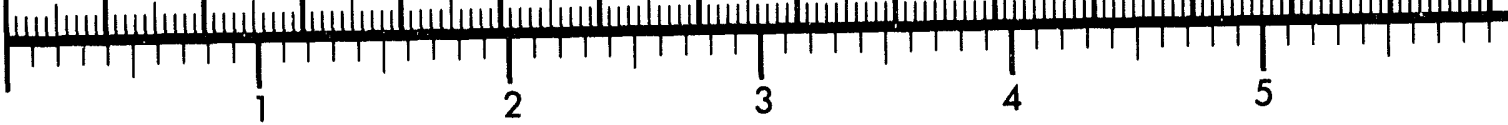
Inches
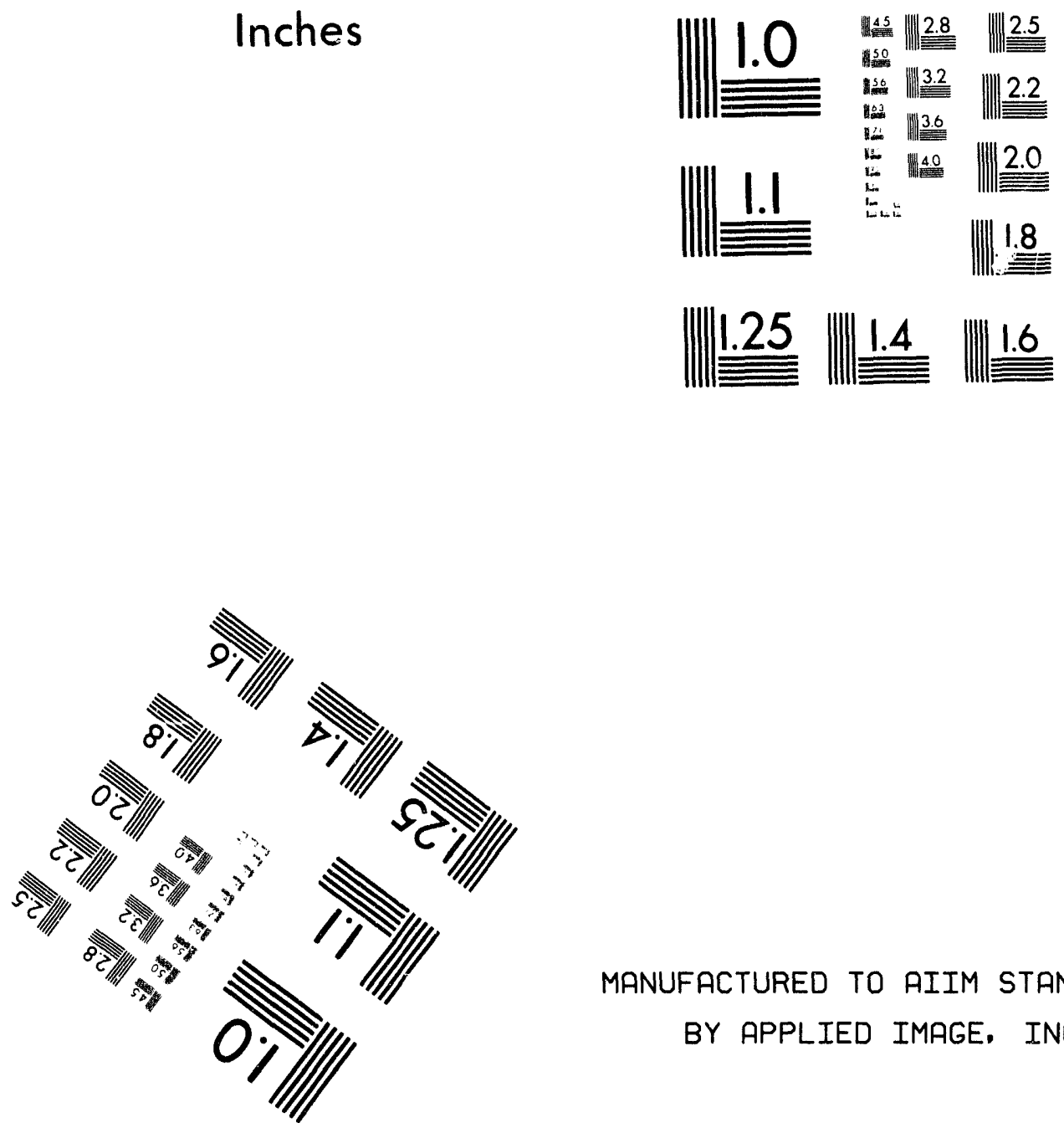

MANUFACTURED TO AIIM STANDARDS

BY APPLIED IMAGE, INC.

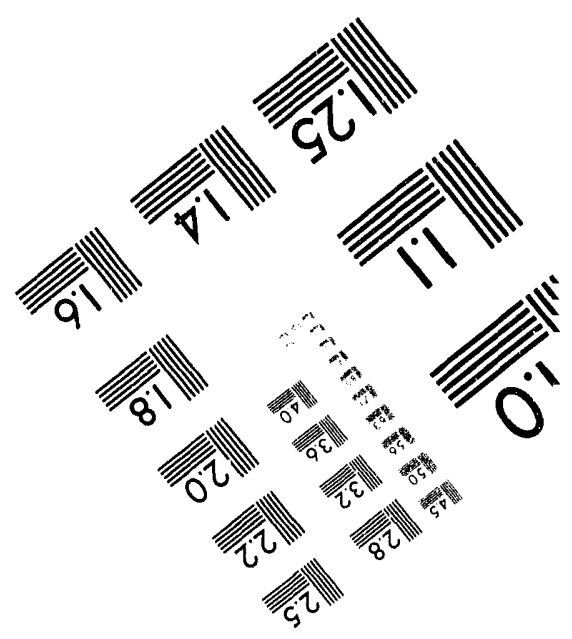



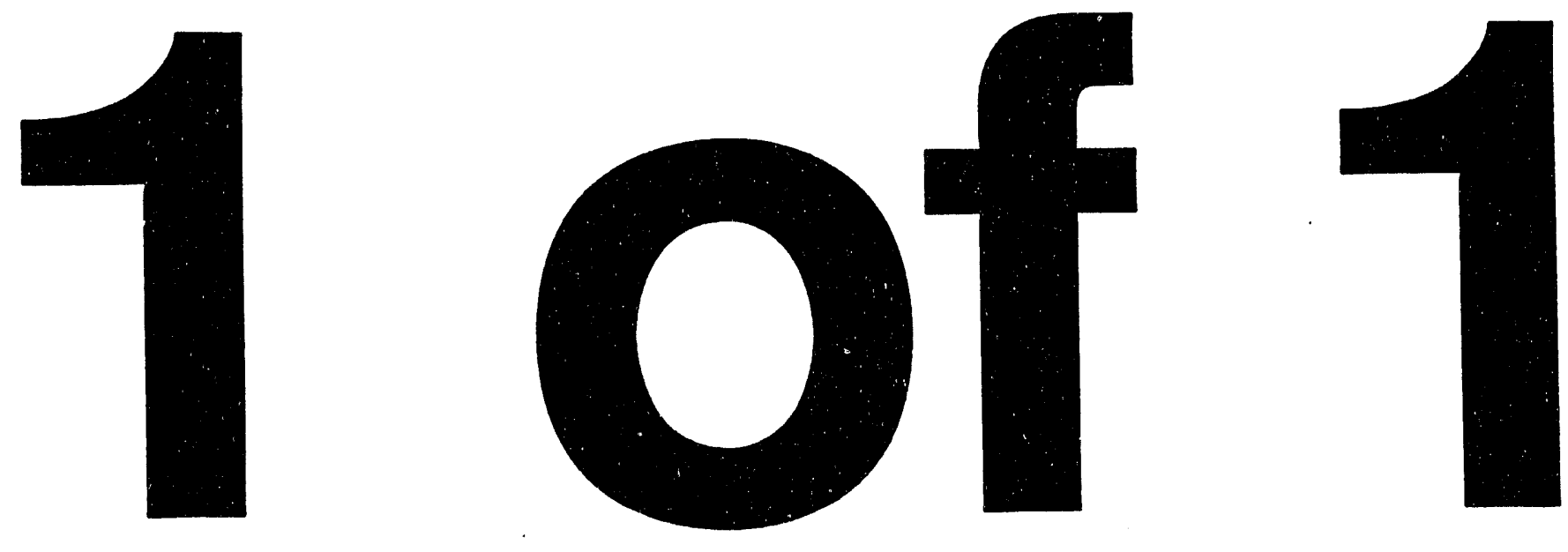
PNL-SA-23531

\section{CATION DISORDER IN HIGH-DOSE, NEUTRON-IRRADIATED SPINEL}

\author{
F. A. Garner \\ G. W. Hollenberg \\ E. Sickafus ${ }^{(a)}$ \\ A. C. Larson ${ }^{(a)}$
}

\author{
M. Nastasi ${ }^{(\alpha)}$ \\ N. $\mathrm{Yu}^{(\mathbf{a})}$ \\ R. C. Bradt ${ }^{(\mathfrak{)})}$
}

August 1994

Presented at the

Proceedings of Fourth Symposium on the Fabrication and

Properties of Ceramics for Fusion Energy at the 96th

Annual Meeting of the American Ceramic Society

April 24-28, 1994

Indianapolis, Indiana

Prepared for

the U.S. Department of Energy

under Contract DE-AC06-76RLO 1830

Pacific Northwest Laboratory

Richland, Washington 99352

(a) Los Alamos National Laboratory, Los Alamos, New Mexico

(b) University of Nevada-Reno, Reno, Nevada

\section{DISCLAIMER}

\footnotetext{
This report was prepared as an account of work sponsored by an agency of the United States Government. Neither the United States Government nor any agency thereof, nor any of their employees, makes any warranty, express or implied, or assumes any legal liability or responsibility for the accuracy, completeness, or usefulness of any information, apparatus, product, or process disclosed, or represents that its use would not infringe privately owned rights. Reference herein to any specific commercial product, process, or service by trade name, trademark, manufacturer, or otherwise does not necessarily constitute or imply its endorsement, recommendation, or favoring by the United States Government or any agency thereof. The views and opinions of authors expressed herein do not necessarily state or reflect those of the United States Government or any agency thereof.
} 
CATION DISORDER IN HIGH-DOSE, NEUTRON-IRRADIATED SPINEL - K. E. Sickafus, A. C. Larson, N. Yu, M. Nastasi (Los Alamos National Laboratory); G. W. Hollenberg and F. A. Garner (Pacific Northwest Laboratory); R. C. Bradt (University of Nevada-Reno).

\section{OBJECTIVE}

The objective of this effort is to determine whether $\mathrm{MgAl}_{2} \mathrm{O}_{4}$ spinel is a suitable ceramic for fusion applications.

\section{SUMMARY}

The crystal structures of $\mathrm{MgAl}_{2} \mathrm{O}_{4}$ spinel single crystals irradiated to high neutron fluences [ $>5 \cdot 10^{26}$ $\left.\mathrm{n} / \mathrm{m}^{2}\left(\mathrm{E}_{\mathrm{n}}>0.1 \mathrm{MeV}\right)\right]$ were examined by neutron diffraction. Crystal structure refinement of the highest dose sample indicated that the average scattering strength of the tetrahedral crystal sites decreased by $\sim 20 \%$ while increasing by $\sim 8 \%$ on octahedral sites. Since the neutron scattering length for $\mathrm{Mg}$ is considerably larger than for $\mathrm{Al}$, this result is consistent with site exchange between $\mathrm{Mg}^{2+}$ ions on tetrahedral sites and $\mathrm{Al}^{3+}$ ions on octahedral sites. Least-squares refinements also indicated that, in all irradiated samples, at least $35 \%$ of $\mathrm{Mg}^{2+}$ and $\mathrm{Al}^{3+}$ ions in the crystal experienced disordering replacements. This retained $d p a$ on the cation sublattices is the largest retained damage ever measured in an irradiated spinel material.

\section{PROGRESS AND STATUS}

\section{Introduction}

Many studies of neutron irradiation-induced damage in spinel bave indicated that spinel is a highly radiation-resistant ceramic. ${ }^{1-9}$ Of the mechanisms underlying spinel's radiation resistance, it is known that the vast majority of point defects generated during irradiation annihilate harmlessly by interstitialvacancy recombination rather than condensing into defect aggregates such as dislocation loops and $\checkmark$ voids. ${ }^{10}$ So, the instantaneous displacement damage in spinel, quantified in terms of displacements per atom or $d p a$, far exceeds the net or retained displacement damage. In fact, electron microscopy observations indicate that, for total neutron doses ranging from $0.1-20 \mathrm{dpa}$, ${ }^{(a)}$ dislocation loops accommodate only $0.002-0.09 \%$ of the total dpa induced during an irradiation (depending on neutron fluence and irradiation temperature). ${ }^{11,14}$ By contrast, in ceramics more susceptible to radiation damage such as $\mathrm{MgO}$ or $\mathrm{Al}_{2} \mathrm{O}_{3},>0.1 \%$ of the total displacements are stabilized in defect aggregates

(a) In this report, total dpa is estimated based on published or calculated neutron fluences and assuming an equivalence of $1 \mathrm{dpa}$ per $10^{25} \mathrm{n} / \mathrm{m}^{2}, \mathrm{E}_{n}>0.1 \mathrm{MeV}$. This estimation factor is within $10 \%$ of the total dpa calculated using the neutron radiation damage codes SPECOMP \& SPECTER ${ }^{11,12}$ for irradiations of the compound alumina $\left(\mathrm{Al}_{2} \mathrm{O}_{3}\right)$ in typical fission reactor in-core positions, assuming threshold displacement energies $\mathrm{E}_{\mathrm{d}}^{\mathrm{Al}}=27 \mathrm{eV} ; \mathrm{E}_{\mathrm{d}}^{\mathrm{O}}=30 \mathrm{eV} \cdot{ }^{13}$ Calculations were made for the HFIR, FFTF, and EBR-II reactors, based on available dosimetry data [ibid.]. 
at similar neutron doses, and vacancy retention can be as high as a few percent. ${ }^{3}$ The question raised in the study presented here is this: Is all of the instantaneous $d p a$ in spinel truly lost, or is some of this dpa hidden in disorder on the cation sublattices?

Cation disorder in spinel is defined in terms of the degree of inversion of the cation sublattices. In "normal" spinel, large $\mathrm{Mg}^{2+}$ ions occupy tetrahedral $(A)$ interstices between oxygen ions, while the smaller trivalent $\mathrm{Al}^{3+}$ ions lie in octahedral $(B)$ interstices. Ionic radii for magnesium aluminate ions, obtained from Shannon and Prewitt, ${ }^{15}$ are shown in Table 1. In an "inverse" spinel, the $A$-sites accommodate only the $\mathrm{Al}^{3+}$ ions, while the $B$-sites are occupied by $\mathrm{Mg}^{2 !}$ and $\mathrm{Al}^{3+}$ ions in equal proportions. The general formula for spinel is given by

$$
\left(\mathrm{Mg}_{1-\mathrm{i}}^{2+} \mathrm{Al}_{\mathrm{i}}^{3+}\right)^{\mathrm{A}_{\mathrm{iv}}}\left[\mathrm{Mg}_{\mathrm{i}}^{2+} \mathrm{Al}_{2-\mathrm{i}}^{3+}\right]_{2}^{\mathrm{B}_{\mathrm{vi}}} \quad \mathrm{O}_{4} \quad \begin{cases}\mathrm{i}=0 & \rightarrow \text { normal spinel } \\ \mathrm{i}=2 / 3 & - \text { random cation arrangement } \\ \mathrm{i}=1 & - \text { inverse spinel }\end{cases}
$$

Table 1. Ionic radii for tetrahedrally $(I V)$ - coordinated $\mathrm{Al}^{3+}, \mathrm{Mg}^{2+}$, and $\mathrm{O}^{2-}$ ions and octahedrally $(V T)$ - coordinated $\mathrm{Al}^{3+}$ and $\mathrm{Mg}^{2+}$ ions.

\begin{tabular}{ccccc}
\hline $\begin{array}{c}\mathrm{r}^{N} \\
\mathrm{Al}^{3+}\end{array}$ & $\begin{array}{c}\mathrm{r}^{N V} \\
\mathrm{Mg}^{2+}\end{array}$ & $\begin{array}{c}\mathrm{O}^{N-} \\
\mathrm{O}^{2-}\end{array}$ & $\begin{array}{c}\mathrm{rl}^{3+} \\
\mathrm{Al}^{3+}\end{array}$ & $\begin{array}{c}\mathrm{r}^{V T} \\
\mathrm{Mg}^{2+}\end{array}$ \\
\hline $0.039 \mathrm{~nm}$ & $0.049 \mathrm{~nm}$ & $0.138 \mathrm{~nm}$ & $0.053 \mathrm{~nm}$ & $0.072 \mathrm{~nm}$ \\
\hline
\end{tabular}

The quantity in parentheses represents the average occupancy of $A$-sites (coordination $I V$ ), while the quantity in brackets represents the average occupancy of $B$-sites (coordination $V T$ ). The variable $i$ is the so-called inversion parameter, which specifies the fraction of trivalent aluminum ions that occupy $A$-sites. Naturally grown magnesium aluminate spinels exhibit approximately the normal spinel structure, so that $i \sim 0$; the same samples annealed at elevated temperature for a few minutes suffer cation inversion as high as $i=0.3{ }^{16}$ It has been demonstrated that synthetic magnesium aluminate is always partly inverse (e.g., ref. 17); inversion values from about $0.1-0.6$ have been observed, the latter representing a nearly random cation arrangement. ${ }^{18,19}$

The goal of the experiments described here is to use neutron diffraction to determine the extent of neutron-induced cation disorder in $\mathrm{MgAl}_{2} \mathrm{O}_{4}$, via measurement of the inversion parameter before and after irradiation. Neutron diffraction is superior to X-ray diffraction for disorder measurements in magnesium aluminate because the neutron scattering length (and likewise the cross-section) for a $\mathrm{Mg}$ nucleus is sufficiently greater than that of $\mathrm{Al}$, so that their site-occupancies may be distinguished. ${ }^{20}$ The X-ray scattering factors for $\mathrm{Mg}^{2+}$ and $\mathrm{Al}^{3+}$ are too similar to reveal site-occupancy distinctions by X-ray diffraction. Evidence will be presented here for significant accommodation of cation disorder in high dose, neutron irradiated spinel crystals. Specifically, neutron scattering data revealed the highest retained $d p a$ ( $\sim 40 \%$ on the cation sublattices) ever measured in spinel with little observed degradation in mechanical properties. ${ }^{21}$ 


\section{Experimental Procedure}

Spinel single crystals with formula $\mathrm{MgO} \cdot x \mathrm{Al}_{2} \mathrm{O}_{3}$, where $x$ is nearly 1 , were obtained from Union Carbide Corporation, San Diego, CA, USA. Details of the crystal purity are given elsewhere. ${ }^{22}$ The crystals were cut into cylindrical pellets from transparent, 2-cm long boules, with [001] growth direction. The pellets were approximately $4.8 \mathrm{~mm}$ in diameter and $2-3 \mathrm{~mm}$ in height. Samples were irradiated in the Materials Open Test Facility (MOTA) of the Fast Flux Test Facility (FFTF). The nominal irradiation conditions experienced by the pellets in the FFTF reactor were $24.9 \cdot 10^{26}$ $\left.n / \mathrm{m}^{2} E_{n}>0.1 \mathrm{MeV}\right)$ at $658 \mathrm{~K}(249 \mathrm{dpa}) ; 5.3 \cdot 10^{26} \mathrm{n} / \mathrm{m}^{2}$ at $678 \mathrm{~K}(53 \mathrm{dpa}) ;$ and $5.6 \cdot 10^{26} \mathrm{n} / \mathrm{m}^{2}$ at $1023 \mathrm{~K}$ $(56 \mathrm{dpa})$. One pellet was not irradiated but stored under ambient conditions as a control sample.

Irradiated crystals were analyzed using the single-crystal diffractometer (SCD) at the Manuel Lujan, Jr. Neutron Scattering Center ( $L A N S C E)$, Los Alamos National Laboratory. The $x-y$ position and time-of-flight (TOF) (the time from the generation of the neutron to detection) are recorded for every neutron detected. The TOF defines the neutron velocity and is directly proportional to its wavelength. The design of the SCD allows for collection of a volume of reciprocal space at each setting of the crystal, in the form of a "histogram." Four histograms were collected to cover the desired portion of reciprocal space, the unique region, $h \geq k \geq l \geq 0$, from each of the samples. The data were collected at $\sim 299 \mathrm{~K}$.

The data reduction and structure refinement were carried out using the diffraction code GSAS (General Structure Analysis System ${ }^{23}$ ). The initial values for the atomic positions input into the crystal structure refinement using $G S A S$ were obtained from Wycoff. ${ }^{24}$ In defining atomic coordinates, two choices for unit cell origin are available in the space group for spinel: the inversion center $\overline{3} m$ or the centei $\overline{4} 3 \mathrm{~m}$, a translation of $\bar{i} \frac{1}{8} \frac{i}{8}$ from center $\overline{3} \mathrm{~m}$. In either case, 24 cations per unit cell are distributed over the equipoints 8(a) and 16(d) (Wycoffs notation), while 32 oxygen anions occupy the equipoint 32(e). In the case of 32(e), the fractional coordinates $x, y$, and $z$ along the cube axes of the unit cell are the same. They are represented by $u$, the so-called oxygen parameter. The significance of $u$ will be discussed later.

During the structure refinement, atomic positions, temperature and occupancy factors, extinction, and $\checkmark$ individual histogram scale factors are varied in a least-squares procedure. Refinement proceeds until calculated reciprocal-space intensities, based on the structure model, best match observed intensities. Because neutrons are scattered from atomic nuclei, which act as point scatterers, the scattering length of an atom does not vary with $d$-spacing. Thus, the scattering length for a site is the weighted linear sum of the scattering lengths of the atoms occupying that site.

The model structure was tested for convergence using the following unweighted and weighted definitions for the residual index: ${ }^{25}$

$$
R=\sqrt{\frac{\sum_{j}\left(\left|F_{j o}\right|-\mid F_{j d}\right)}{\sum_{j} F_{j o}}}
$$

$$
R_{w}=\sqrt{\frac{\sum_{j} W_{j}|| F_{j o}|-| F_{j c}||^{2}}{\sum_{j} W_{j} F_{j o}^{2}}}
$$


where $F_{j o}$ and $F_{j c}$ are proportional to the observed and calculated scattering factors at reciprocal-space position $j$, respectively; $w_{j}$ is the weight assigned to the intensity at position $j$, equal to the inverse of the counting error (i.e., the square root of the observed intensity) at position $j$.

\section{$\underline{\text { Results }}$}

1. Scattering Power and Cation Inversion.

Table 2 shows the results of the crystal structure refinements, based on the neutron diffraction data obtained from unirradiated and irradiated spinel samples. The only constraint in these refinements is that oxygen sites are fully occupied by oxygen anions. Normalized, average scattering powers are shown for $A$ - and $B$-site cations and for oxygen anion sites. Also indicated in Table 2 are the residual indices from the crystal structure refinement for each sample. The $A$-site (8(a)) scattering power, $\hat{f}_{\mathrm{A}}$ is normalized by the coherent neutron scattering length for magnesium, $b_{M g}=5.375 \mathrm{fm}$. Similarly, the scattering power $\hat{f}_{\mathrm{B}}$ for the $B$-site $(16(\mathrm{~b}))$ is normalized by $b_{A l}=3.449 \mathrm{fm}$, while $\hat{f}_{\mathrm{O}}$ for the oxygensite $(32(\mathrm{e}))$ is normalized by $b_{O}=5.805 \mathrm{fm}$. Coherent neutron scattering lengths (which are analogous to the atomic form factors $f$ in X-ray scattering) were obtained from Koester et al. ${ }^{26}$

Table 2. Scattering power of tetrahedral and octahedral cation sites, and oxygen anion lattice sites, in unirradiated and neutron irradiated spinel crystals. Also tabulated are the residual indices from the crystal structure refinement for each crystal.

\begin{tabular}{lccccccc}
\hline & \multicolumn{3}{c}{ Scattering Power (normalized) } & & \multicolumn{2}{c}{ Residual Index } \\
\cline { 2 - 3 } \multicolumn{1}{c}{ Sample } & $\hat{f}_{\mathrm{A}}$ & $\begin{array}{c}\hat{f}_{\mathrm{B}} \\
\text { A-Site 8(a) }\end{array}$ & B-Site 16(d) & $\begin{array}{c}\hat{f}_{\mathrm{O}} \\
\text { O-Site 32(e) }\end{array}$ & & $\mathrm{R}$ & $\mathrm{R}_{\mathrm{W}}$ \\
\hline Unirradiated & 0.862 & 1.001 & 1.000 & & 0.076 & 0.065 \\
$56 \mathrm{dpa} / 1023 \mathrm{~K}$ & 0.765 & 1.167 & 1.000 & & 0.095 & 0.099 \\
$53 \mathrm{dpa} / 678 \mathrm{~K}$ & 0.756 & 1.123 & 1.000 & & 0.112 & 0.103 \\
$249 \mathrm{dpa} / 658 \mathrm{~K}$ & 0.687 & 1.086 & 1.000 & & 0.107 & 0.096 \\
\hline
\end{tabular}

It is readily apparent in Table 2 that the scattering powers of both $A$ - and $B$-cation sites in spinel are changed following neutron irradiation. It is observed that the average scattering power of an $A$-site diminishes following irradiation, while the scattering power of a $B$-site increases. Since the scattering length for $\mathrm{Mg}$ is much larger than for $\mathrm{Al}$, these results suggest that the higher scattering power $\mathrm{Mg}$ atoms are replaced by $\mathrm{Al}$ atoms on $A$-sites and vice versa on $B$-sites, during neutron irradiation.

To determine the extent of inversion in each crystal, an additional constrained least-squares refinement procedure was performed. The initial condition for this refinement procedure was a normal spinel lattice. The refinement required that (i) all $A$ and $B$ sites be occupied by a $\mathrm{Mg}$ or $\mathrm{Al}$ atom; (ii) occupancy of an $A$-site by an $\mathrm{Al}$ atom required simultaneous occupancy of a $B$-site by a $\mathrm{Mg}$ ion; (iii) the Al:Mg atom ratio in the crystal was fixed at 2:1. A summary of the results is presented in Table 3 . Fig. 1 shows schematically the inversion parameter results; here, $i$ is seen to increase from $i \sim 0.24$ in 
Table 3. Least-squares refinement results for inversion parameter, oxygen parameter, and residual indices for unirradiated and neutron irradiated spinel single crystals.

\begin{tabular}{lcccccc}
\hline \multicolumn{1}{c}{ Sample } & $\begin{array}{c}\text { Inversion } \\
\text { Parameter }(i)\end{array}$ & \multicolumn{2}{c}{ Oxygen Parameter $(u)$} & \multicolumn{1}{c}{$\begin{array}{c}\text { Residual } \\
\text { Index }\end{array}$} \\
\hline & & $\frac{3 m}{2}$ & $\frac{43 m}{2}$ & & $\frac{\mathrm{R}}{0}$ & $\frac{\mathrm{R}_{\mathrm{w}}}{0.066}$ \\
Unirradiated & $.237 \pm .020$ & $.237371 \pm .000049$ & $.387629 \pm .000049$ & 0.074 & 0.066 \\
$56 \mathrm{dpa} / 1023 \mathrm{~K}$ & $.644 \pm .016$ & $.241627 \pm .000049$ & $.383373 \pm .000049$ & 0.093 & 0.072 \\
$53 \mathrm{dpa} / 678 \mathrm{~K}$ & $.592 \pm .026$ & $.241924 \pm .000077$ & $.383076 \pm .000077$ & 0.115 & 0.092 \\
$249 \mathrm{dpa} / 658 \mathrm{~K}$ & $.692 \pm .026$ & $.241845 \pm .000073$ & $.383155 \pm .000073$ & 0.109 & 0.099 \\
\hline
\end{tabular}

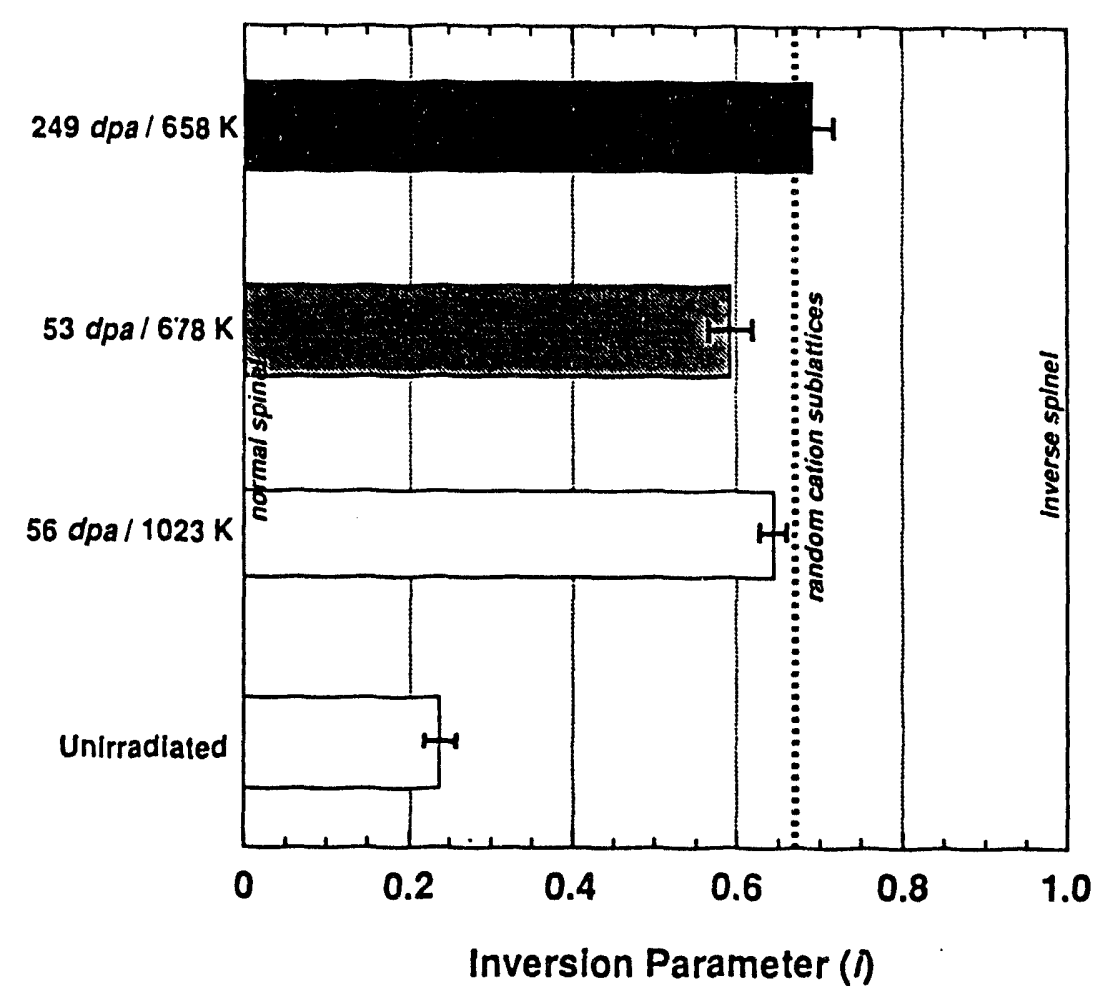

Fig. 1. Plot of the cation inversion parameter $i$ for unirradiated and irradiated spinel single crystals, as determined from least-squares structure refinements of neutron diffraction data.

the unirradiated sample to inversion values ranging from 0.59 to 0.69 in the neutron irradiated samples. In fact $i \sim 0.69$ for the highest fluence sample $(249 \mathrm{dpa}$ ) exceeds the value of $i$ pertaining to randomized cation sublattices $(i=0.67)$. 
These results suggest that in all neutron irradiated spinel samples, at least $35 \%$ of the $A$-sites (or equivalently, $\sim 17 \%$ of the $B$-sites) in the irradiated spinel crystals have experienced $\mathrm{Al}^{3+}$ for $\mathrm{Mg}^{2+}$ disordering replacements. This retained $d p a$ on the cation sublattices is the largest retained $d p a$ ever measured in an irradiated spinel material (as discussed earlier, only $0.002-0.09 \%$ of the instantaneous $d p a$ has ever been observed in the microstructure of irradiated spinel).

\section{The Oxygen Parameter}

Additional, indirect evidence for cation disorder in irradiated spinel crystals is obtained from determination of the oxygen parameter, $u$, in the crystal structure refinement. The following discussion refers to the schematic diagram in Fig. 2. Here are shown two interpenetrating tetrahedra that make up the basic structural unit in the spinel crystal lattice. One tetrahedron consists of an $A$-site cation coordinated by four oxygen anions. The second tetrahedron consists of an oxygen anion, coordinated by one $A$-site and three $B$-site cations.

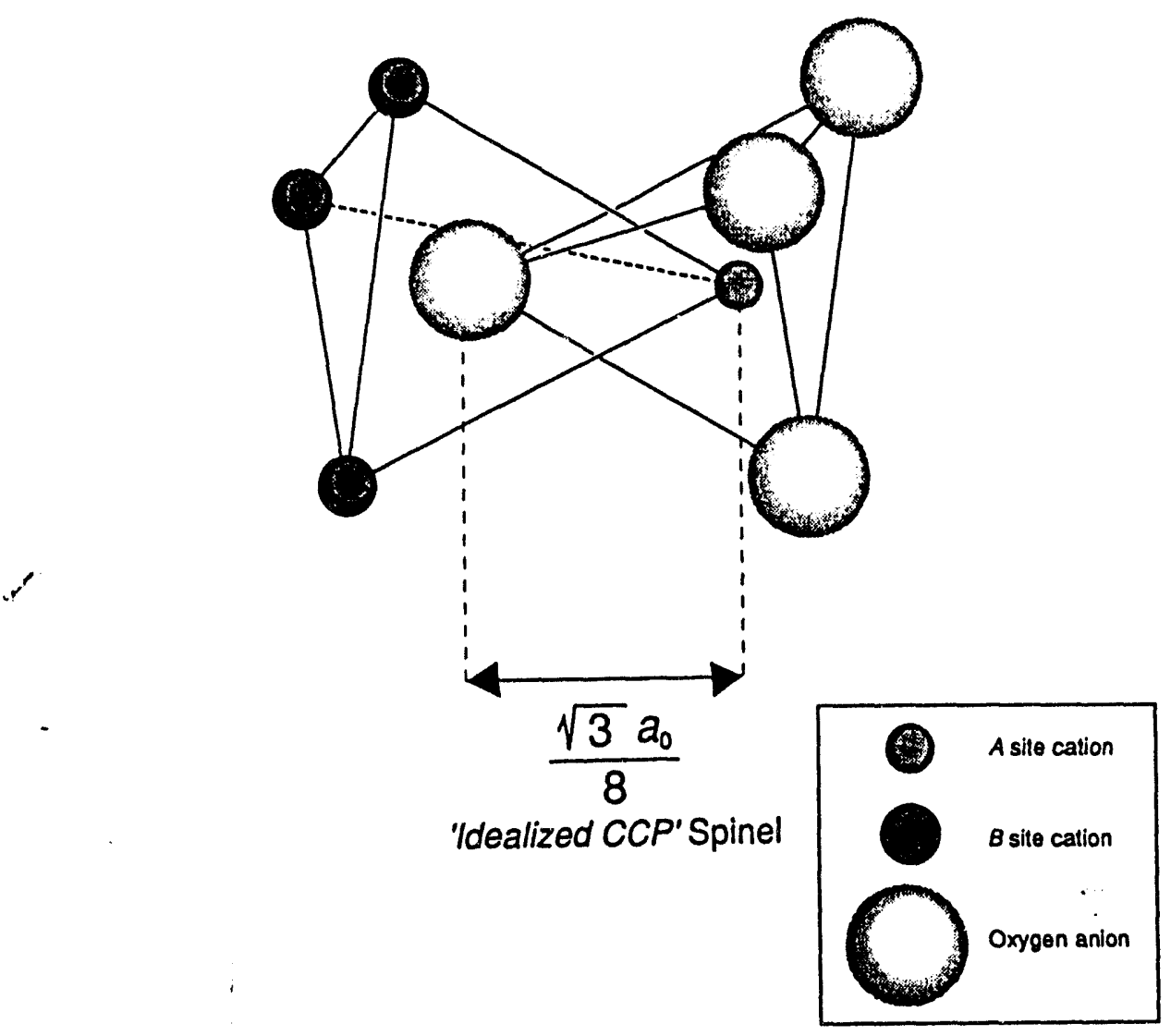

Fig. 2. Schematic diagram of the fundamental structural unit in spinel: two interpenetrating tetrahedra. One tetrahedron consists of an $A$-site cation coordinaled by four oxygen anions. The second tetrahedron consists of an oxygen anion, coordinated by one $A$-site and three $B$-site cations. All ions are drawn smaller than their actual radii. $B$-site cations are drawn slightly larger than their $A$-site counterparts, as in Fig. 1. Also shown is the Oxygen - to - $A$-site bond length for a "perfect cubic close-packed" anion sublattice. 
The oxygen parameter arises because, in real spinel crystals, the oxygen lattice is not "idealized CCP (cubic close-packed)." This is attributable in part to the fact that each divalent cation $\left(\mathrm{Mg}^{2+}\right)$ in the lattice is too large to fit into one of the comparatively small tetrahedral $A$ interstices; consequently the surrounding $\mathrm{O}^{2-}$ ions expand outwards by equal displacements along the body diagonals of the cube. If this dilatation did not take place, the bond length between an $\mathrm{O}^{2-}$ anion and an $A$-site cation would be precisely $1 / 8$ of the body-diagonal of the unit cell; i.e., $0.125 \cdot \sqrt{3} a_{0}$, where $a_{0}$ is the lattice parameter. In crystal structure refinements of $\mathrm{MgAl}_{2} \mathrm{O}_{4}$, a significant oxygen dilatation is always observed (Wycoff $\mathrm{f}^{24}$ ). This dilatation is usually reported in terms of the oxygen parameter, $u: u$ is the fraction of the cubic unit cell edge defining the position of the oxygen ion at fractional coordinates $u$, $u, u$. For idealized $C C P$ oxygen packing, $u=0.375$ for unit cell origin at $\overline{4} 3 m ; u=0.250$ for unit cell origin at $\overline{3} \mathrm{~m}$. Wycoff ${ }^{24}$ reports $u(\overline{4} 3 \mathrm{~m})=0.387$ or $u(\overline{3} \mathrm{~m})=0.262$ for natural $\mathrm{MgAl}_{2} \mathrm{O}_{4}$. This represents an O-to-A-site bond length of $0.137 \cdot \sqrt{3} a_{0}$. In the crystal structure refinements for the unirradiated spinel samples in this study, similar values were obtained: $u(\overline{4} 3 \mathrm{~m})=0.3876$ or $u(\overline{3} \mathrm{~m})=$ 0.2626 ; O-to- $A$-site bond length $=0.1376 \cdot \sqrt{3} a_{0}$.

Now, consider the case in which a divalent $\mathrm{Mg}^{2+}$ ion exchanges places with a trivalent $\mathrm{Al}^{3+}$ ion. This positions a much smaller cation in the $A$ interstice than before $\left(\mathrm{r}_{\mathrm{A}}^{J} \mathrm{~V}^{3+}=0.039 \mathrm{~nm} ; \mathrm{r}_{\mathrm{Mg}}^{I V}=0.049 \mathrm{~nm}\right.$; Table 1). This, in turn, should relax the dilatation previously imposed on the surrounding oxygen ions. If, by irradiation for instance, one induces a significant number of $\mathrm{Mg}^{2+} / \mathrm{Al}^{3+}$ site excharges within the crystal lattice, the O-to- $A$-site bond length should relax toward the idealized $C C F$ val se of $0.125^{\circ}$ $\sqrt{3} a_{0}$. This is precisely what is found in the neutron irradiated samples. Fig. 3 shows crystal structure refinement results for the O-to- $A$-site bond length and the oxygen parameter $u$ for all of the spinel crystals measured in this study. It is clear that the O-to- $A$-site bond length and $u$ shift toward their idealized $C C P$ values after neutron exposure. Also, changes in these parameters apparently saturate with neutron fluence. For instance, both the 53 and $249 \mathrm{dpa}$ samples irradiated at $\sim 670 \mathrm{~K}$ show the same value for the O-to- $A$-site bond length $\left(0.1330 \cdot \sqrt{3} a_{0}\right)$. These results indicate, in accordance with the scattering power results presented earlier, that $\mathrm{Mg}^{2+}$ ions increasingly occupy $B$-sites and $\mathrm{Al}^{3+}$ ions increasingly occupy $A$-sites as irradiation progresses.

\section{Interstitial Sites}

Some evidence was found for occupied interstitial sites in the irradiated spinel single crystals. This $\checkmark$ was determined by examining Fourier transform difference maps of the neutron diffraction data. Four such maps are shown in Fig. 4, where the unirradiated sample (Figs. 4a and 4c) is compared to the $53 \mathrm{dpa} / 678 \mathrm{~K}$ neutron irradiated sample (Figs. $4 \mathrm{~b}$ and $4 \mathrm{~d}$ ). These maps are equivalent to a display of the difference between $\mathbb{F}_{j 0} \mid$ and $\mathbb{F}_{j c} \mid$ at each reciprocal lattice po ition $j$. Contours in these maps represent real-space regions of nuclear density (i.e., neutron scattering length) which produce scattered intensity in the observed diffraction pattern that is not accounted for in the calculated or model structure factor. In Fig. 4, the model structure factors are obtained from the unconstrained leastsquares refinement presented earlier. The maps in Fig. 4 represent slices along the $<111>$ crystallographic axis. The center of Figs. $4 a$ and $4 b$ is at unit cell fractional coordinates $3 / 24,3 / 24,3 / 24$, relative to a $\overline{3} m$ origin. The center of Figs. $4 c$ and $4 d$ is at unit cell fractional coordinates $5 / 24,5 / 24$, $5 / 24$, relative to a $\overline{3} m$ origin. ${ }^{(a)}$ These layers are special because in an idealized spinel structure, they are empty interstitial layers. No atoms should be located in these planes.

(a) A different convention for the occupation of equipoints by cations is used in Fig. 4 than described earlier. Cations here are distributed over equipoints $8(b)$ and $16(c)$ rather than $8(a)$ and $16(d)$. 


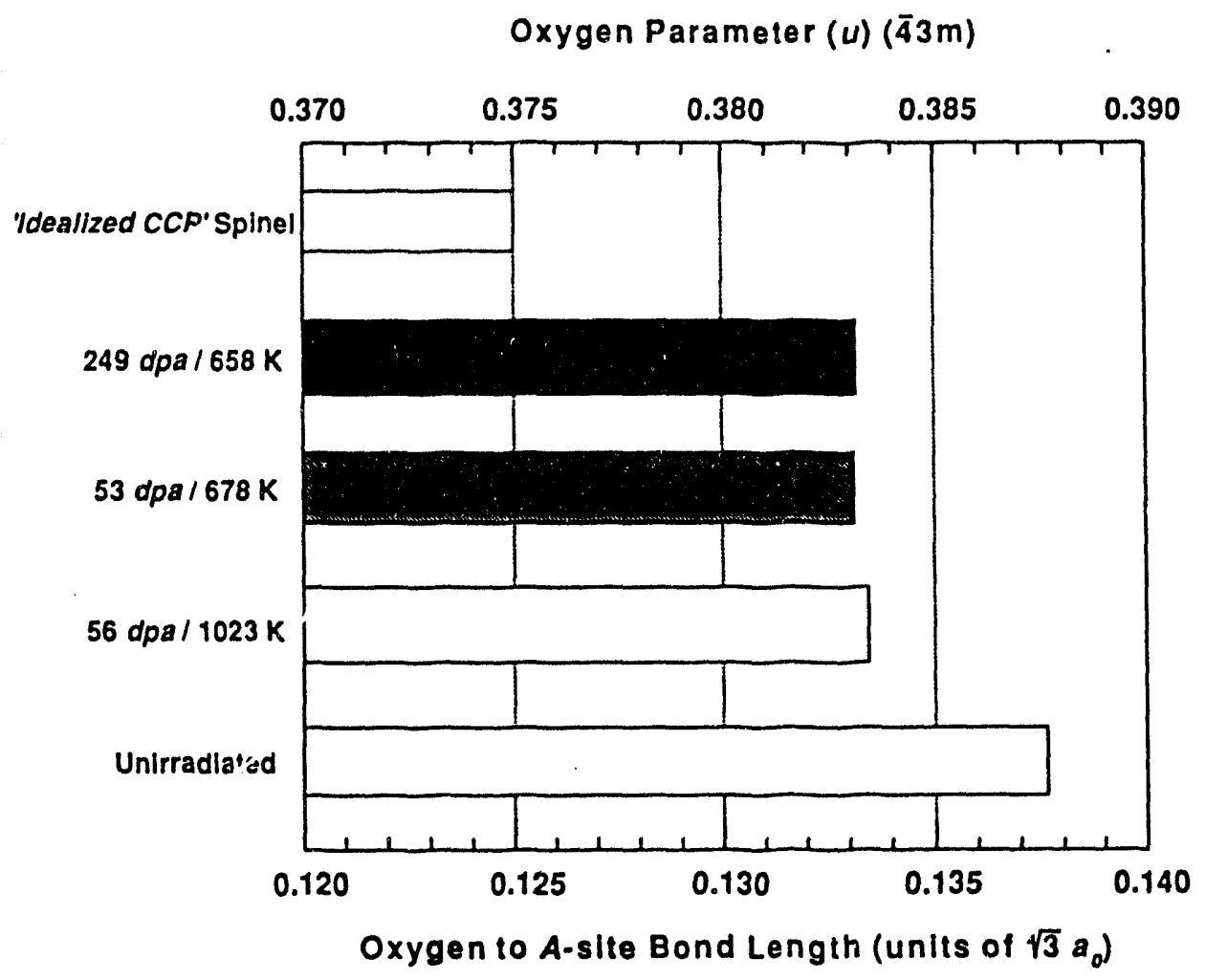

Fig. 3. Histogram showing the Oxygen to $A$-site bond length and oxygen parameter $u$ (for the $\overline{4} 3 m$ origin) for unirradiated and irradiated spinel single crystals. Values were determined from the crystal structure refinement using GSAS. Also shown is the Oxygen-to- $A$-site bond length and $u$ for an "idealized cubic close-packed" anion sublattice.

In the case of the unirradiated sample, almost no neutron scattering length is present in the Fourier difference maps of Fig. 4, at least in terms of a statistically appreciable quantity. However, in the irradiated sample, regions are observed where statistically significant nuclear densities reside. These are indicated by arrows in Figs. 4b and 4d. The symmetry of these locations in the maps is highly suggestive of at least partial occupancy of these interstitial sites by cations following irradiation. Work is in progress to quantify the retained $d p a$ at these sites. Fourier difference maps were also obtained from other layers along $<111>$ that contain cations in some, but not all, cation interstitial sites for a given layer. Evidence was also found for the partial occupation of interstitial sites following neutron irradiation. However, this effect is easiest to see in the completely vacant layers, as demonstrated in Fig. 4.

\section{CONCLUSIONS}

In this study, it was found by neutron diffraction that the average scattering power of an occupied, tetrahedral $(A)$ site diminished by $\sim 20 \%$ while increasing by $\sim 8 \%$ on octahedral $(B)$ sites at the highest neutron fluence investigated $(\sim 250 \mathrm{dpa})$. By least-squares refinement of the diffraction 


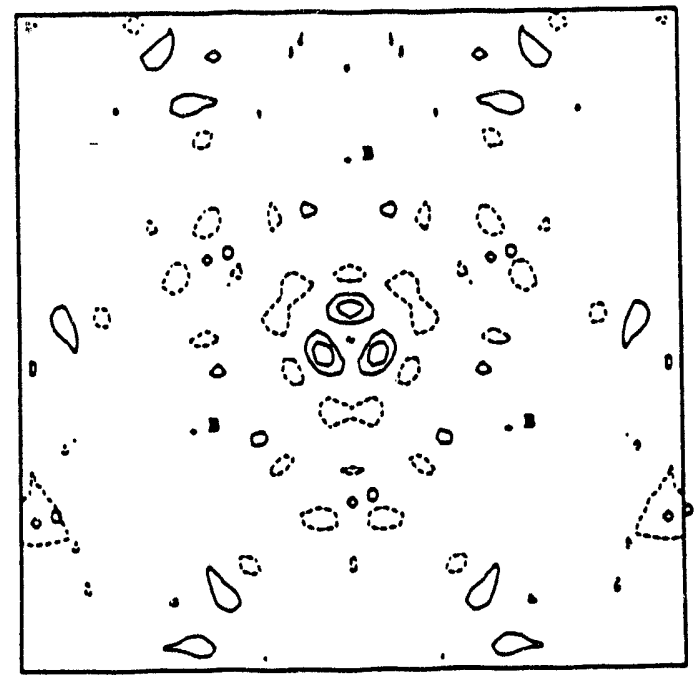

(a)

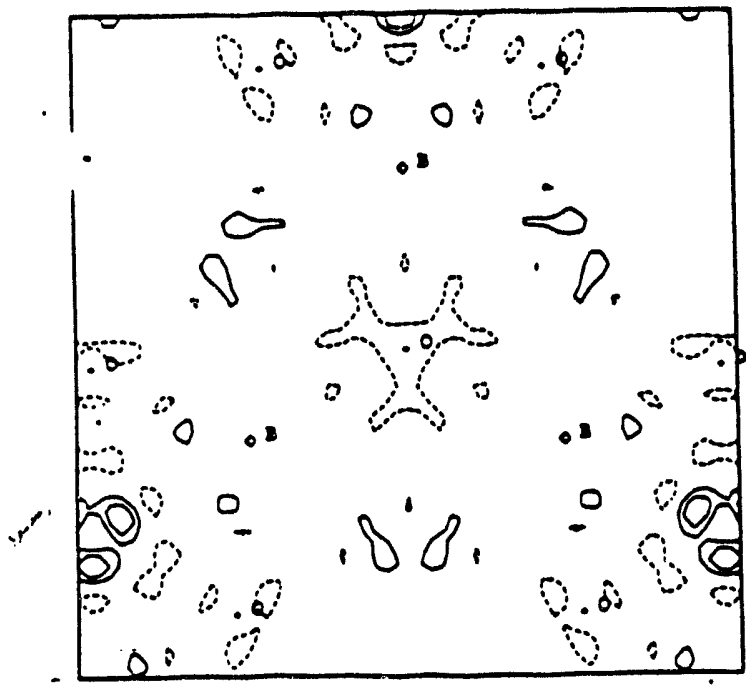

(b)

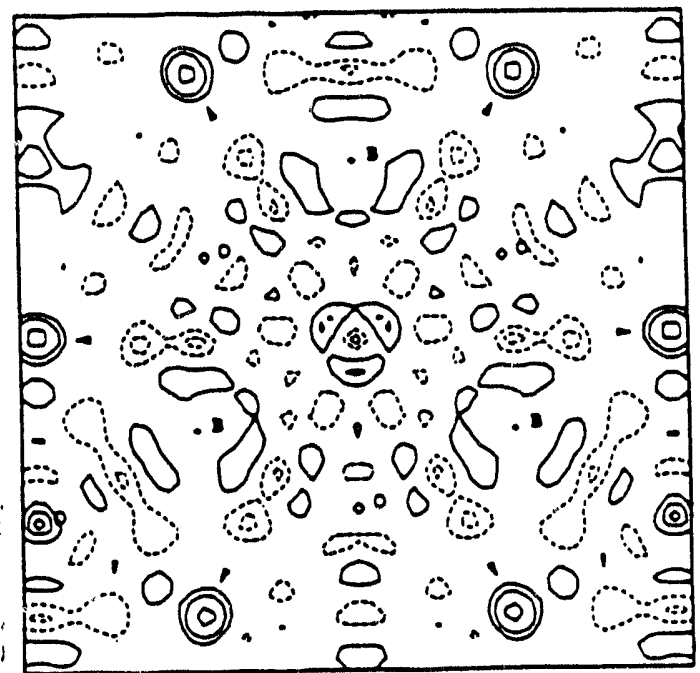

(c)

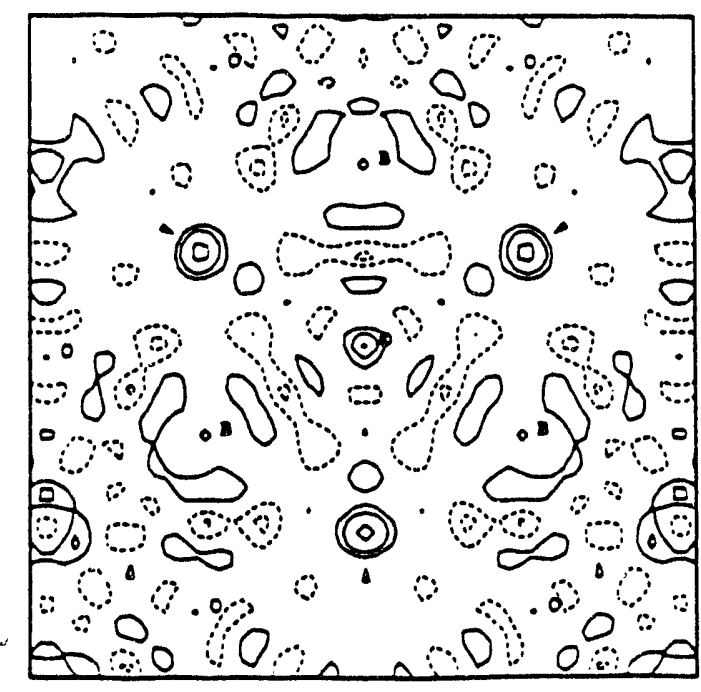

(d)

Fig. 4. Fourier transform difference maps of the neutron diffraction data for the unirradiated sample (a,c) compared to the $53 \mathrm{dpa} / 678 \mathrm{~K}$ neutron-irradiated sample (b,d). Maps represent real space slices along the $<111>$ crystallographic axis. The dimensions of each map are $0.6 \mathrm{~nm}$ by $0.6 \mathrm{~nm}$. The center of (a) and of (b) is at unit cell fractional coordinates $3 / 24,3 / 24,3 / 24$, relative to a $3 \mathrm{~m}$ origin. The center of (c) and of (d) is at unit cell fractional coordinates $5 / 24,5 / 24,5 / 24$, relative to a $3 m$ origin. See text for discussion. 
data, the inversion parameter, $i$, was found to increase from $i \sim 0.24$ (unirradiated) to $i \sim 0.6$ to 0.7 , in the neutron-irradiated samples $(>50 \mathrm{dpa})$. From these measurements, it is estimated that $\sim 35 \%$ of the cation sites have experienced $\mathrm{Mg}^{2+}$ for $\mathrm{Al}^{3+}$ or $\mathrm{Al}^{3+}$ for $\mathrm{Mg}^{2+}$ ion exchange. This retained $d p a$ on the cation sublattices is the largest retained $d p a$ ever measured in an irradiated spinel material (only $0.002-0.09 \%$ of the instantaneous $d p a$ has ever been observed in irradiated spinel crystal microstructure). Measurements of O-to- $A$-site bond length and the oxygen parameter $u$ provide additional indirect evidence for cation disorder in irradiated samples. Also, the latter measurements indicate that, upon neutron exposure in excess of $\sim 50 \mathrm{dpa}$, cation disorder effects are saturated (for irradiations at $\sim 670 \mathrm{~K})$. The cation disorder measured in this study likely represents the majority of the retained damage in irradiated spinel.

The results cited here indicate that interstitial-vacancy recombination is a highly efficient point defect annihilation mechanism in spinel, even when it leads to disorder on the cation sublattices of the crystal. Due to the high efficiency of interstitial-vacancy recombination, the condensation of point defects into aggregates such as dislocation loops and voids is of little consequence in irradiated spinel. The ability of spinel to accept cation sublattice disorder suggests that additional radiation-resistant ceramics may be found in multicomponent oxides where cation disorder is easily accommodated.

\section{Acknowledgments}

This work was performed for the U.S. Department of Energy (DOE), Office of Basic Energy Sciences, Division of Materials Sciences; and also supported by DOE under Contract DE-AC06-76RLO 1830. Pacific Northwest Laboratory is operated for DOE by Battelle Memorial Institute.

\section{Expected Achievements in the Next Reporting Period}

This segment of the work is complete. 


\section{$\underline{\text { References }}$}

1. G. F. Hurley and J. M. Burch, Am. Ceram. Soc. Bull. 59 (1980) 456.

2. G. F. Hurley, J. C. Kennedy, F. W. Clinard Jr., R. A. Youngman, and W. R. McDonell, J. Nucl. Mater. 103/104 (1981) 761.

3. F. W. Clinard, Jr., G. F. Hurley, and L. W. Hobbs, "Neutron Irradiation in $\mathrm{MgO}, \mathrm{Al}_{2} \mathrm{O}_{3}$, and $\mathrm{MgAl}_{2} \mathrm{O}_{4}$ Ceramics," J. Nucl. Mater. 108/109 (1982) 665-670.

4. F. W. Clinard, Jr., G. F. Hurley, and R. W. Klaffky, Res. Mech. 8 (1983) 207.

5. F. W. Clinard, Jr., G. F. Hurley, L. W. Hobbs, D. L. Rohr, and R. A. Youngman, J. Nucl.Mater. 122/123 (1984) 1386.

6. F. W. Clinard, Jr., G. F. Hurley, R. A. Youngman, and L. W. Hobbs, J. Nucl. Mater. 133/134 (1985) 701.

7. C. A. Parker, L. W. Hobbs, K. C. Russell, and F. W. Clinard, Jr., J. Nucl. Mater. 133/134 (1985) 741.

8. Y. Fukushima, T. Yano, T. Maruyama, and T. Iseki, J. Nucl. Mater. 175 (1990) 203.

9. H. Suematsu, T. Iseki, T. Yano, Y. Saito, T. Suzuki, and T. Mori, J. Am. Ceram. Soc. 75 (1992) 1742.

10. L. W. Hobbs and F. W. Clinard, Jr., "Faulted Defect Aggregates in Neutron-Irradiated $\mathrm{MgAl}_{2} \mathrm{O}_{4}$ Spinel," Joumal de Physique 41 (1980) C6-232-236.

11. L. R. Greenwood, "SPECOMP Calculations of Radiation Damage in Compounds," in Reactor Dosimetry: Methods, Applications, and Standardization, ASTM STP 1001, Harry Farrar IV and E. P. Lippincott, Eds., American Society for Testing and Materials, Philadelphia (1989) 598-602.

12. L. R. Greenwood and R. K. Smither, "SPECTER: Neutron Damage Calculations for Materials Irradiations," Argonne National Laboratory Report ANL/FPP/TM-197, 1985.

13. L. R. Greenwood, private communication (1994).

14. C. Kinoshita, K. Fukumoto, and K. Nakai, "Electron-, Ion-, and Neutron-Irradiation Damage in Ceramics," Ann. Chim. Fr. 16 (1991) 379-389.

15. R. D. Shannon and C. T. Prewitt, "Effective Ionic Radii in Oxides and Fluorides," Acta. Cryst. B25 (1969) 925-946.

16. U. Schmocker, H. R. Boesch, and F. Waldner, "A Direct Determination of Cation Disorder in $\mathrm{MgAl}_{2} \mathrm{O}_{4}$ Spinel by ESR," Phys. Lett. 40A(3) (1972) 237-238.

17. E. Brun, S. Hafner, P. Hartmann, and F. Laves, "Elektrische Quadrupolwechselwirkung von ${ }^{27} \mathrm{Al}$ und Kationenverteilung in Spinell $\left(\mathrm{MgAl}_{2} \mathrm{O}_{4}\right)$," Naturwissenschaften 47 (1960) 277. 
18. E. Stoll, P. Fischer, W. Hälg, and G. Maier, "Redetermination of the Cation Distribution of Spinel $\left(\mathrm{MgAl}_{2} \mathrm{O}_{4}\right)$ by Means of Neutron Diffraction," J. Physique, Paris 25 (1964) 447-448.

19. U. Schmocker and F. Waldner, J. Phys. C9 (1976) L235-237.

20. G. E. Bacon, "A Neutron-Diffraction Study of Magnesium Aluminum Oxide," Acta Cryst. 5 (1952) 684-686.

21. C. A. Black, F. A. Garner, and R. C. Bradt, "Influence of High Dose Neutron Irradiation at 385 and $750^{\circ} \mathrm{C}$ on the Microhardness of $\mathrm{MgAl}_{2} \mathrm{O}_{4}$ Spinel," Fusion Reactor Semiannual Progress Report DOE/ER-0313/15, Oak Ridge, Tennessee (1994) 508-514.

22. F. A. Garner, G. W. Hollenberg, J. L. Ryan, Z. Li, C. A. Black, and R. C. Bradt, "Dimensional Stability, Optical and Elastic Properties of $\mathrm{MgAl}_{2} \mathrm{O}_{4}$ Spinel Irradiated in FFTF to Very High Exposures," Fusion Reactor Semiannual Progress Report DOE/ER-0313/15, Oak Ridge, Tennessee (1994) 502-507.

23. A. C. Larson and R. B. VonDreele, "General Structure Analysis System (GSAS)," LA-UR 86-748, Los Alamos National Laboratory, Los Alamos, New Mexico (1990).

24. R.W.G. Wycoff, Crystal Structures V. 3: Inorganic Compounds $\left.R_{x i} M X_{4}\right)_{y}, R_{x}\left(M_{n} X_{p}\right)_{y}$, Hydrates and Ammoniates, 2nd ed., John Wiley \& Sons, New York (1965) 76.

25. J. E. Post and D. L. Bish, "Rietveld Refinement of Crystal Structures Using Powder X-ray Diffraction Data," in Reviews in Mineralogy, Vol. 20: Modem Powder Diffraction, Eds. D. L. Bish and J. E. Post, Mineralogical Society of America (Bookcrafters, Inc. Chelsea, Michigan) (1989) 333-367.

26. L. Koester, H. Rauch, and E. Seymann, Atomic Data and Nuclear Data Tables 49 (1991) 66. 

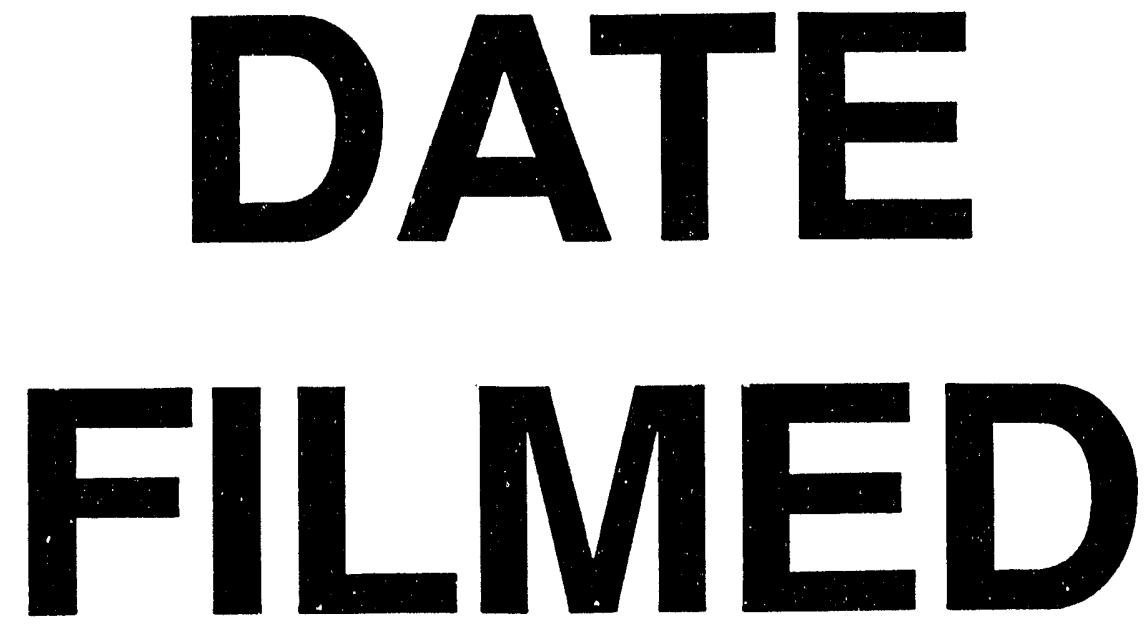

\section{$10 / 17 / 94$}
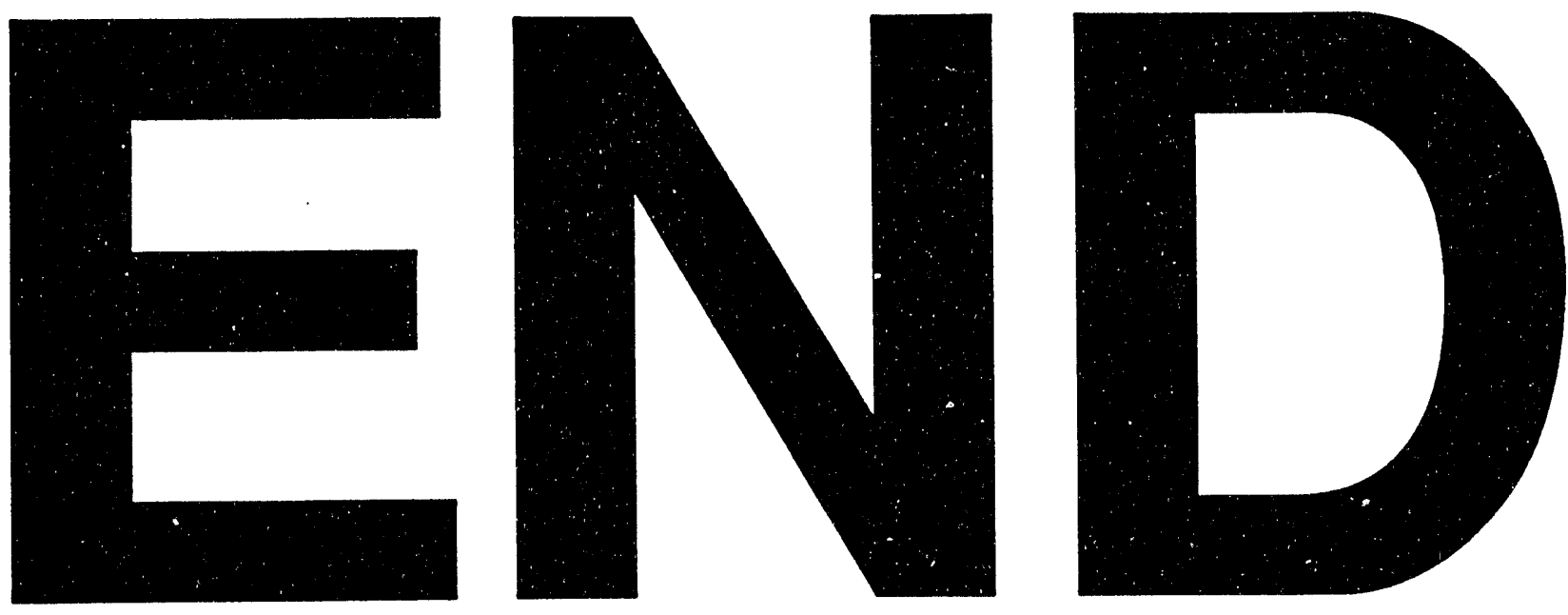
